\title{
3D AERODROME OBSTACLE ASSESSMENT USING STEREO REMOTE SENSING IMAGERY
}

\author{
L. Mitsevich \\ Moscow State University of Geodesy and Cartography, Faculty of Applied Cosmonautics and Photogrammetry, 105064 MIIGAiK \\ \#4, Gorokhovsky pereulok, Moscow, Russia - mila.skygeo@gmail.com
}

ISPRS TC II, WG II/4-II/10

KEY WORDS: Stereo Imagery, Aerodrome Obstacle Data, Limitation Surfaces, Photogrammetry for Air Navigation

\begin{abstract}
:
The paper reveals the photogrammetric methods of the aerodrome obstacle data collection and assessment in accordance with the International Civil Aviation Organization (ICAO) requirements. High artificial or natural vertical objects (obstacles) near a runway can cause accidents during aircraft take-off and landing. There are a series of limitation surfaces defining allowable obstacle heights. Identification and assessment of obstacles extending above the limitation surfaces are important steps for aerodrome certification. To this end, the periodic aerodrome obstacle survey procedure is implemented mostly by ground geodetic methods. The goal of the research was to develop the technology for remote and effective obstacle identification and assessment processes using remote sensing stereo imagery. The photogrammetric methods were based on the three-dimensional vector models that were integrated into the stereo pair of satellite and aviation scanner images. The obstacle extends above the limitation surfaces evaluated in a semiautomatic mode, mathematically and visually controlled. The advantages of the stereo photogrammetric methods are discussed. The ecological aspects of precise evaluation of forested areas as critical obstacles considered. Examples of the implementation of this technology for aerodromes of the Republic of Belarus are given.
\end{abstract}

\section{INTRODUCTION}

The safe movement at aerodromes and near-aerodrome territories in the areas of aircraft takeoff, landing, and maneuvering is an important parts of air traffic safety. Terrain and obstacle data are key geospatial components of aeronautical information. There are international regulatory documents of ICAO (International Civil Aviation Organization) (ICAO Annex 14, 2016) and state aviation rules determining the requirements for terrain and obstacles data collection and assessment. According to ICAO requirements, there are limitation surfaces showing the maximum permissible object heights in the of aircraft movement areas.

The geodetic methods based on ultra-high-resolution satellite data are recommended for obtaining terrain and obstacle data (ICAO Annex 15, 2016). The choice of methods or their combination depends on the professional and technical equipment of the geodetic data provider.

When studying the features of aeronautical information, changing requirements for accuracy, formats, and update frequency, it is obvious that ground-based geodetic methods are time-consuming and inefficient. With this method, it is necessary to identify all obstacles within a radius of $15 \mathrm{~km}$ from the aerodrome reference point (ARP), and then evaluate whether the objects intersect the limitation surfaces, before selecting only those that are extended above surfaces (critical obstacles). The main disadvantage is the redundancy of determined, registered, and then rejected objects, since it is not clear on the ground if objects would be crossing the limitation surface.
The extension of vertical objects above the limitation surfaces is estimated by mathematical calculations of the surface altitude at the point of intersection. Significant efforts are required to input geodetic data from coordinate tables to the aeronautical database and convert them to special formats. The object completeness control is also difficult as well as the polygonal object vertical coordinate detection. When it is necessary to eliminate forest area partly, the segmentation is impossible using this method.

Some cloud-based photogrammetric techniques solve the problems of object completeness and correct object heights by the creation of a digital elevation/situation model (DEM, DSM). Studies using UAS LIDAR imagery are used as a primary source of the vertical data (Demir, Poli, Baltsavias, 2009; Parrish, Nowak, 2009). Though a detailed DSM is an advantage of a LIDAR point cloud, the main flaws are the probability of frangible (antennas, power lines) points or linear obstacle loss. Moreover, there are technical difficulties associated with UAS flying over an operating aerodrome due to radio frequency interference. The problem of selecting, evaluating, and converting obstacle data into the aeronautical formats also remains.

Examples of software to execute these tasks are Transoft Solution (Germany), ArcGIS for Aviation (USA), and OMEGA (RISK, Azerbaijan). The general function of these programs is to manage aeronautical information databases. All of them have specific data input interfaces and process tools. To achieve correct operation, the basic knowledge in air navigation, programming, and geoinformatics is required. The processing of 
geospatial data in such programs requires mutual multi-step conversion data to geodetic and aeronautical formats, which might cause loss of data integrity. To assess the correctness and completeness of information, interdisciplinary training and knowledge is required.

The aim of research was to develop a technology combining the aerodrome obstacle identification and assessment processes in a digital photogrammetric system using a stereo pair of remote sensing images as the primary source of geospatial data. The tasks were the following: vectoring three-dimensional models of limitation surfaces, creating an optimized obstacle data array, mathematical control of measurement accuracy, and minimizing data integrity loss during conversion.

\section{TECHNOLOGY}

\subsection{Materials}

The research was carried out in the digital photogrammetric workstation (DPW) PHOTOMOD (PHOTOMOD Development Team, 2019). The program tools of remote sensing data triangulation, raster and vector data process modules, digital terrain modeling tools were involved. A geographic information database structure and coordinate system designer blocks were implemented for data conversion and control.

The study areas were the aerodromes of the Republic of Belarus. The terrain and obstacle data were explored at radius of $15 \mathrm{~km}$ from the runway thresholds (the points of the limitation surfaces lower border). The accuracy requirements for terrain and obstacle data for the area of work are $5 \mathrm{~m}$ for horizontal coordinates and $3 \mathrm{~m}$ for vertical coordinates (ICAO Annex 15, Nov., 2016).

The stereo images of the high-resolution remote sensing data and the digital aviation scanner (ADS-100) data were used as sources of geospatial data and the basis for 3D stereo modeling (Figure 1).



Figure 1. The ADS-100 stereo image (2018)

To prepare the images for photogrammetric measurements, they were geo-positioned using ground control points or exterior orientation elements according to their technical characteristics (Table 1).

\begin{tabular}{|c|c|c|c|}
\hline № & Parameter & $\begin{array}{c}\text { Remote } \\
\text { sensing data }\end{array}$ & $\begin{array}{c}\text { ADS-100, } \\
\text { L1 level }\end{array}$ \\
\hline 1 & $\begin{array}{c}\text { Spatial resolution } \\
\text { (image pixel size), } \mathrm{m}\end{array}$ & 0.5 & 0.3 \\
\hline 2 & $\begin{array}{l}\text { Area covered by one } \\
\text { stereo pair, } \mathrm{km}^{2}\end{array}$ & $\geq 100$ & \begin{tabular}{|c|}
$5 \mathrm{~km}$ wide \\
stereo blocks \\
with $5-10 \%$ \\
overlap \\
\end{tabular} \\
\hline 3 & Cloud cover, \% & $0-5$ & $0-5$ \\
\hline 4 & $\begin{array}{l}\text { The need for reference } \\
\text { points }\end{array}$ & $\begin{array}{c}\text { Yes. } \\
\text { Estimated as } \\
1 / 10 \mathrm{~km}^{2}\end{array}$ & $\begin{array}{c}\text { No. } \\
\text { Georeferenced } \\
\text { by on board } \\
\text { GNSS and } \\
\text { CORS }^{1}\end{array}$ \\
\hline 5 & $\begin{array}{l}\text { Aerial triangulation } \\
\text { accuracy, max. } \\
\text { residuals, m }\end{array}$ & 0.7 & $\begin{array}{c}\text { External } \\
\text { orientation } \\
\text { elements are } \\
\text { imported }\end{array}$ \\
\hline 6 & $\begin{array}{l}\text { The accuracy in stereo } \\
\text { mode }(0.5 \text { pix }), m\end{array}$ & 0.25 & 0.15 \\
\hline 7 & $\begin{array}{l}\text { The accuracy of } \\
\text { determining objects } \\
\text { coordinates, } \mathrm{m}\end{array}$ & 0.5 or better & 0.3 or better \\
\hline 8 & $\begin{array}{l}\text { Total maximum object } \\
\text { height measuring error } \\
\text { in stereo, } \mathrm{m}\end{array}$ & 0.95 & 0.45 \\
\hline
\end{tabular}

Table 1. Stereo images technical parameters ${ }^{2}$

Technical information regarding the sizes and coordinates of the aerodrome elements was obtained from published aeronautical information (AIP), relevant at the time of the study. The calculation of the geometry of obstacle limitation surfaces was carried out in accordance with the rules of restriction and elimination of obstacles (ICAO Annex 14, 2016).

EUROCONTROL standards and practices were applied to control the procedure and rules for identification and obstacle segmentation (EUROCONTROL, 2015). International standards were applied to convert obstacle data into exchange formats (RTCA DO-272C/EUROCAE ED-99C, 2011).

In accordance with ICAO requirements (ICAO DOC-9674, 2002), vector and raster datasets were reduced to the coordinate system WGS-84 (ITRF-2005), and a universal projection of the Mercator (UTM) of the northern hemisphere appropriate zone was performed ${ }^{3}$.

\subsection{Methods}

Photogrammetric methods of aerodrome obstacle inspection technology were combined in three stages. The present article

\footnotetext{
${ }^{1}$ CORS - constantly operated reference system - satellite geodetic network

${ }^{2}$ Information on the geodetic accuracy of stereo images was obtained from the technical reports of the Topographic and Geodetic State Enterprise BELGEODESY (Belarus) and is summarized for reference.

${ }^{3}$ As per ICAO standards, it is recommended to use the EGM-96 geoid model or to demonstrate the conversion parameters from another geoid model.
} 
provides an example of a natural obstacle survey ${ }^{4}$. For the inspection of artificial obstacles, the same sequence was applied.

Stage 1. Construction of the obstacle limitation surfaces. The calculation of the geometry of three-dimensional vector models of the surfaces was performed according to the category of an aerodrome runway. For different categories of aerodromes, the size of the airfield, the distances to the lower boundaries of the surfaces, and the initial altitudes are different. Inclinations, horizontal extent, and heights of nodal points of the surfaces should be calculated for the runway category. The following surfaces were calculated and vectorized:

1. Outer horizontal surface;

2. Conical surface;

3. Inner horizontal surface;

4. Approach surface;

5. Transitional surface;

6. Take-off climb surface.

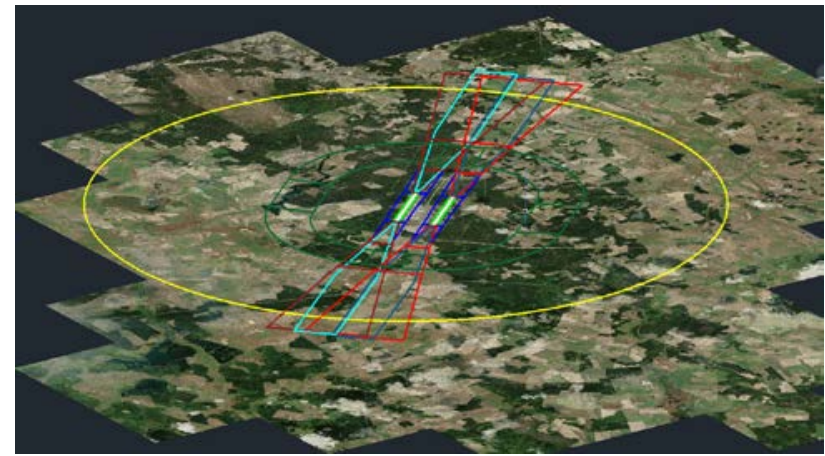

Figure 2. The obstacle limitation surfaces

The geometry of the surfaces was different due to the difference in category. Therefore, for the international aerodrome intended for heavy types of aircraft, the take-off surface slope was $1.2 \%$. The upper boundary of the surface at a distance of $15 \mathrm{~km}$ from the threshold exceeded the threshold height by $180 \mathrm{~m}$. For the local aerodrome, the take-off surface was built with a vertical slope of $2 \%$ and an excess of $300 \mathrm{~m}$, since this airfield is intended for middle and small aircraft.

Due to different geolocation, terrain and construction features, the complex of limitation surfaces is unique for an aerodrome but can be used many times for any geo-referenced images of the aerodrome. Three-dimensional vector models of surfaces can be created in the DPW PHOTOMOD or imported in the exchange formats ArcGIS (*SHP) and AutoCAD (*DXF).

Stage 2. Obstacle identification. Identification of natural obstacles represented by forest stands or terrain forms. The operator performed visual stereo decryption and general analysis of the situation. In the stereoscopic mode, object heights, heterogeneity, and relation to the surfaces can be measured with the accuracy of the half-pixel size. Only objects that penetrate or are closest to the height of the surfaces were determined. Thus, visual selection was determined to be the optimal. If segmenting forest areas was necessary, the area was divided into squares with a side of $100 \mathrm{~m}$, in which 1 point with

\footnotetext{
${ }^{4}$ According to aviation rules, natural woods crossing limitation surfaces must be lowered or removed. However, the forests concerned are under protection and demand a sparing attitude.
}

the highest tree height was selected. Due to the need for a gentle approach to forest stands, the areas to be eliminated were selected very carefully and vectorized by the most penetrating tree tops (Figure 3).

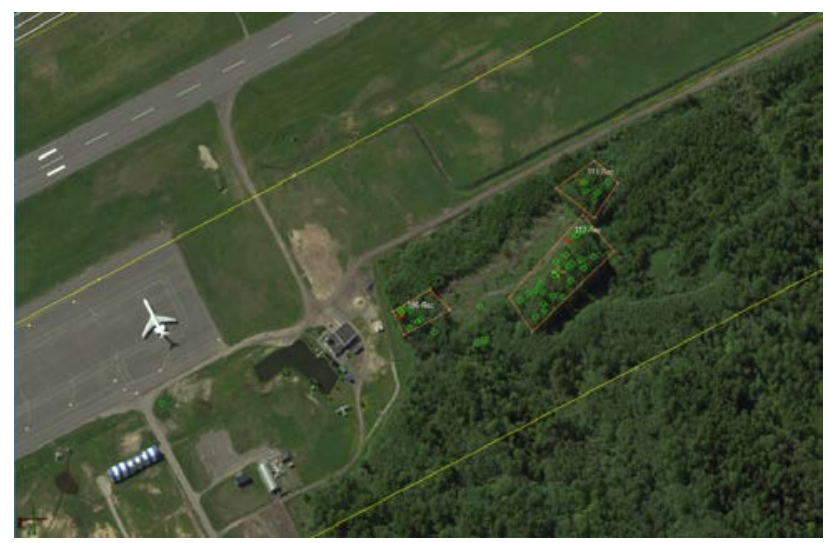

Figure 3. The example in which wood penetrates a transitional surface

Forest vegetation segments (polygons) and individual trees (points) were marked and identified in accordance with the required data structure and stored as vector objects with a set of attribute information (Figure 4).

Stage 3. The obstacle assessment. Assessment of penetration into the limitation surfaces was carried out in a semi-automatic mode using a 3D dense model of the surface by comparing the height of the measured point with the height of the surface at the intersection point.



Figure 4. The take-off climb surface 3D dense model and a vector attribute structure

The program options specify the selection of positive (negative) values. The selection of points in the surface area and recording of the object attributes and its relative height was performed automatically. Objects that were geometrically outside this surface did not participate in the selection. After performing a consistent assessment on each surface, the database of obstacles was exported to exchange formats and was ready to generate reporting documentation for the aerodrome. Vector models of limitation surfaces and arrays of obstacles can serve as the basis for schemes and aeronautical maps.

Stage 4. Control. To control the accuracy and evaluate the cumulative error of the photogrammetric measurements independently, the formulas for calculating the limiting surface 
heights at the point of the obstacle intersection and its extent above the surface were used. In Table 2, the calculations and PHOTOMOD vector attribute data are compared.

\begin{tabular}{|c|c|c|c|c|c|c|c|}
\hline 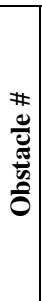 & $\underline{\Xi}$ & $\underset{\nu}{\Xi}$ & $\hat{N}$ & 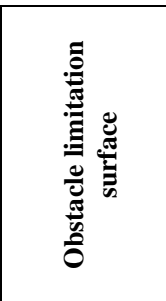 & 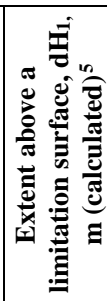 & 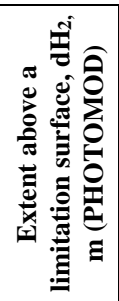 & 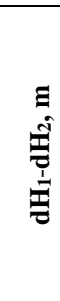 \\
\hline 1 & 2 & 3 & 4 & 5 & 6 & 7 & 8 \\
\hline 1 & 707 & 0 & 199.0 & $\begin{array}{c}\text { Approach } \\
\text { surface }\end{array}$ & -5.7 & -5.7 & -0.0 \\
\hline 2 & 557 & 0 & 196.6 & $\begin{array}{c}\text { Approach } \\
\text { surface }\end{array}$ & -5.1 & -5.1 & -0.0 \\
\hline 3 & -1708 & -311 & 234.0 & $\begin{array}{c}\text { Transitional } \\
\text { surface }\end{array}$ & 7.9 & 8.0 & -0.1 \\
\hline 4 & -3520 & 3 & 214.0 & $\begin{array}{c}\text { Take-off } \\
\text { climb surface }\end{array}$ & -6.2 & -6.2 & 0.0 \\
\hline 5 & 562 & 0 & 196.5 & $\begin{array}{l}\text { Approach } \\
\text { surface }\end{array}$ & -5.3 & -5.4 & 0.1 \\
\hline 6 & -3508 & -3 & 224.0 & \begin{tabular}{c|} 
Take-off \\
climb surface
\end{tabular} & 4.1 & 4.1 & -0.0 \\
\hline 7 & -1508 & 233 & 211.6 & $\begin{array}{c}\text { Transitional } \\
\text { surface }\end{array}$ & -2.2 & -2.4 & 0.2 \\
\hline 8 & -1502 & -331 & 219.0 & $\begin{array}{c}\text { Transitional } \\
\text { surface }\end{array}$ & -8.8 & -8.5 & -0.3 \\
\hline 9 & 448 & -2 & 195.9 & $\begin{array}{l}\text { Approach } \\
\text { surface }\end{array}$ & -3.7 & -3.7 & 0.0 \\
\hline 10 & 998 & $\mid-72$ & 207.7 & $\begin{array}{c}\text { Approach } \\
\text { surface }\end{array}$ & -2.9 & -2.8 & -0.1 \\
\hline
\end{tabular}

Table 2 Control calculations

Calculations were made in the local coordinate system of the aerodrome relative to the ARP, thresholds as reference points for the limitation surfaces. This technology is used by the aerodrome services for internal calculations and preparation of reporting documentation.

In the coordinate system designer PHOTOMOD, a local topocentric coordinate system was defined with the center at the threshold of the runway, the $X$ axis, the continuation of the runway, and the $\mathrm{Y}$ axis, supplementing the system to the right (Figure 5). The obstacle coordinates were converted from the WGS-84 coordinate system to the threshold coordinate system.

As shown in Table 2, the mismatch (column 8) of the PHOTOMOD obstacle extents compared to calculations as per aviation rules (columns 6, 7) was rare and had an acceptable error.

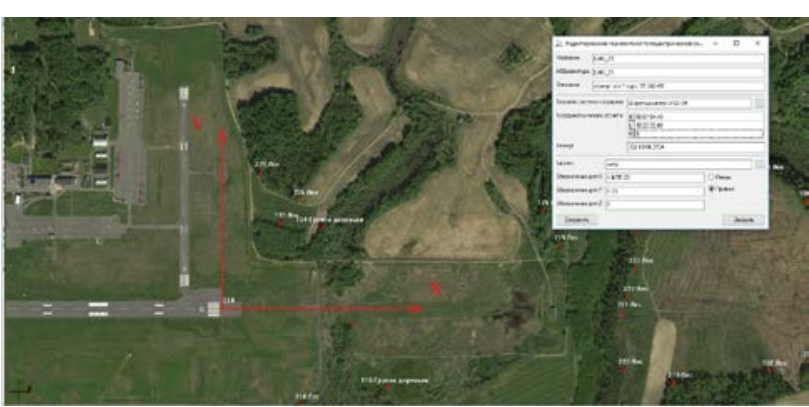

Figure 5 The local topocentric coordinate system

\section{CONCLUSIONS}

\subsection{Results}

A photogrammetric technology for identifying and assessing aerodrome obstacles was created by $3 \mathrm{D}$ modeling in a stereo pair of remote sensing images as the primary source of relevant geospatial data. The accuracy and reliability of absolute and relative measurements of coordinates were mathematically proved.

The efficiency of the remote methods for examining objects inaccessible for geodetic surveying were confirmed. Due to the wide DPW PHOTOMOD functionality, when combining the processes of obstacle identifying and assessment, the excessive object detection and geodata integrity loss were minimized or excluded.

The technology has been successfully tested for two aerodromes where the identification and elimination of critical obstacles was required. There results were checked against the relevant remote sensing data as shown on the Figure 6.

In the left photo (ADS-100, 2018), vast forested areas were in the field of take-off climb and approach surfaces (red lines). In the right photo (satellite, 2019), there is visible that forest obstacles were removed.

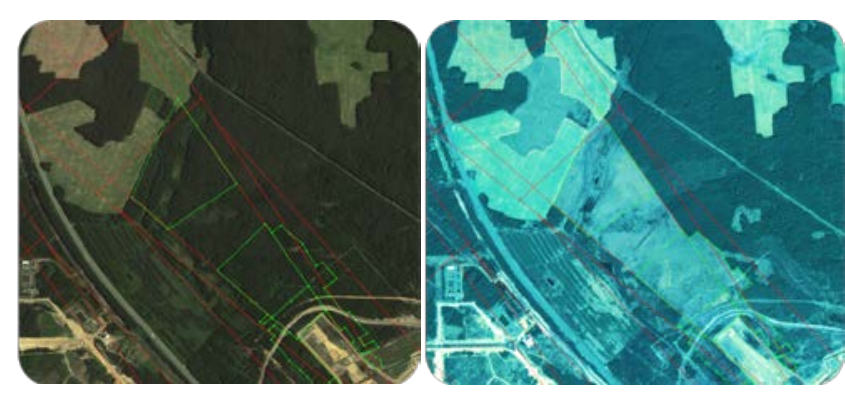

Figure 6 The removed forest obstacles

Economic benefit was derived by a significant conservation of time and resources with a high performance at all work stages compared to traditional ground-based survey methods. The results of the work were positively assessed by the aerodrome and air navigation services. Compliance with ICAO international standards was confirmed by the ICAO IAC expert organization (Moscow).

\footnotetext{
${ }^{5}$ Formulas for calculating surface heights are given in aviation rules (ICAO Annex 14, 2016).
} 


\subsection{Fields of application}

The photogrammetric technology for obstacle inspection combined with geoinformation structures can be used by aerodrome and air navigation services to solve the following problems:

Monitoring the dynamics of aerodrome objects according to the latest remote sensing data. The program functionality is suitable for combining electronic data arrays of various origins coordinate tables, 2D, 3D vector and raster data, and LIDAR and radar survey point clouds.

Planning for the construction of new facilities on the aerodrome territory. To select a site or determine the maximum permissible height of a building, a three-dimensional model of the designed building can be created (imported) at the chosen place of a stereo model and evaluated against the limitation surfaces.

Selection of the territory for the construction of a new airfield in a forest or mountainous area. A three-dimensional model of the runway and limitation surfaces can be imported into the stereo pair space. The most optimal position is selected considering protruding terrain forms and a gentle approach to the elimination of woody vegetation.

The technology is intended for geodetic survey organizations, aerodrome projection and reconstruction, aeronautical chart and route mapping, aviation simulators. The article may be useful to professionals in the field of photogrammetry and remote sensing data for solving problems of air navigation and modeling of geospatial data based on stereo decryption.

\section{ACKNOWLEDGEMENTS}

The author expresses sincere appreciation and gratitude to colleagues of the Photogrammetry Department of the State Enterprise BELGEODESY, and the Director Sergey Zabagonsky; to the Deputy Director of the MINSK-2 airport Alexander Burakov, and the Expert of the Aviation Department of the Republic of Belarus Vadim Pozdeev; to the Moscow State University of Geodesy and Cartography Professor Alexander Chibunichev.

\section{REFERENCES}

Demir, N., Baltsavias, E. (2007). Object extraction at airport sites using DTMs/DSMs and multispectral image analysis. ISSN 36 (3/W49B), 25-30.

Demir, N., Poli, D., Baltsavias, E. (2009). Detection of buildings at airport sites using images \& LIDAR data and a combination of various methods. IAPRS, XXXVIII (Part 3/W4), 71-76.

EUROCONTROL. (2015). Terrain and Obstacle Data Manual (2.1 ed.). Eurocontrol-GUID-0158.

URL: https://www.eurocontrol.int/publication/eurocontrolterrain-and-obstacle-data-manual

ICAO Annex 14. (2016). International Standards and Recommended Practices for Aerodromes - Aerodrome Design and Operations. (6 ed., Vol. I). ICAO.
ICAO Annex 15. (Nov., 2016). International Standards and Recommended Practices. Aeronautical Information Services (15 ed.). ICAO.

ICAO DOC-9674. (2002). World Geodetic System-1984 (WGS84) Manual (2 ed.). ICAO.

URL:http://store1.icao.int/index.php/catalogsearch/result/?q=D oc +9674

Parrish, C., Nowak, R. (May 2009 г.). Improved approach to LIDAR airport obstruction surveying using full-waveform data. Journal of Surveying Engineering, 135(2). doi:10.1061/(ASCE)0733-9453(2009)135:2(72)

PHOTOMOD Development Team. (2019). Digital Photogrammetric Workstation PHOTOMOD. (M. R. RACURS, Ed.) Retrieved from www.en.racurs.ru: https://en.racurs.ru/upload/iblock/f66/PHOTOMOD_en.pdf

RTCA DO-272C/EUROCAE ED-99C. (Sept. 28, 2011). User Requirements for Aerodrome Mapping Information.

URL:https://global.ihs.com/doc_detail.cfm?\&input_search_filte r=EUROCAE\&item_s_key=00536609\&item_key_date =840231 \&input_doc_number=EUROCAE\%20ED\%2D99C\&input_doc _title=\&org_code=EUROCAE 